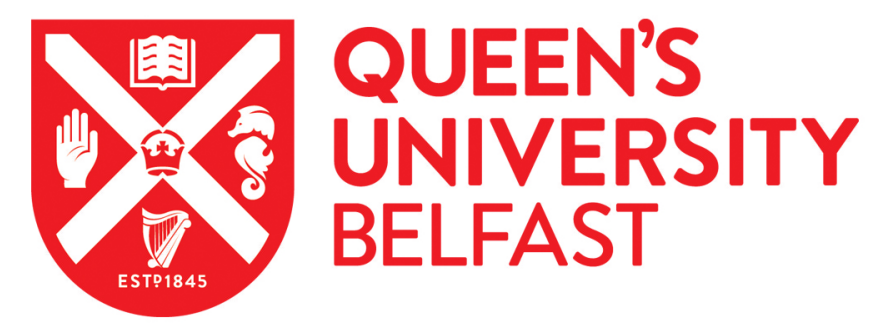

\title{
Synthesis, Photophysical, and Electrochemical Properties of Pyrenes Substituted with Donors or Acceptors at the 4- or 4,9-Positions
}

Ji, L., Krummenacher, I., Friedrich, A., Lorbach, A., Haehnel, M., Edkins, K., Braunschweig, H., \& Marder, T. B. (2018). Synthesis, Photophysical, and Electrochemical Properties of Pyrenes Substituted with Donors or Acceptors at the 4- or 4,9-Positions. Journal of Organic Chemistry, 83(7), 3599-3606. https://doi.org/10.1021/acs.joc.7b03227

Published in:

Journal of Organic Chemistry

Document Version:

Peer reviewed version

Queen's University Belfast - Research Portal:

Link to publication record in Queen's University Belfast Research Portal

Publisher rights

(C) 2018 American Chemical Society.

This work is made available online in accordance with the publisher's policies. Please refer to any applicable terms of use of the publisher.

\section{General rights}

Copyright for the publications made accessible via the Queen's University Belfast Research Portal is retained by the author(s) and / or other copyright owners and it is a condition of accessing these publications that users recognise and abide by the legal requirements associated with these rights.

Take down policy

The Research Portal is Queen's institutional repository that provides access to Queen's research output. Every effort has been made to ensure that content in the Research Portal does not infringe any person's rights, or applicable UK laws. If you discover content in the Research Portal that you believe breaches copyright or violates any law, please contact openaccess@qub.ac.uk. 


\section{Synthesis, Photophysical, and Electrochemical Properties of Pyrenes Substituted with Donors or Acceptors at the 4- or 4,9-Positions}

Lei Ji, Ivo Krummenacher, Alexandra Friedrich, Andreas Lorbach, ${ }^{+}$Martin Haehnel, Katharina Edkins, ${ }^{\dagger}$ Holger Braunschweig, Todd B. Marder*

Institut für Anorganische Chemie and Institute for Sustainable Chemistry \& Catalysis with Boron, Julius-Maximilians-Universität Würzburg, Am Hubland, 97074 Würzburg, Germany
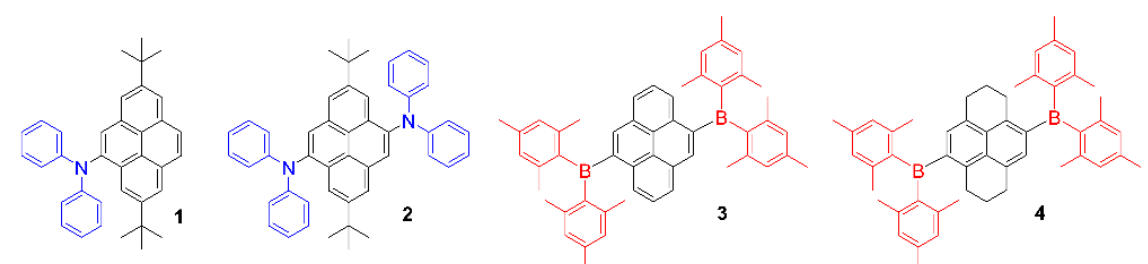

ABSTRACT: We report herein an efficient and direct functionalization of the 4,9-positions of pyrene by Ir-catalyzed borylation. Three pinacol boronates (-Bpin), including 4-(Bpin)-2,7-di-(tert-butyl)pyrene

4,9-bis(Bpin)-2,7-di-(tert-butyl)pyrene

(6), and 4,10-bis(Bpin)-2,7-di-(tert-butyl)pyrene (7) were synthesized. The structures of $\mathbf{6}$ and 7 have been confirmed by single-crystal X-ray diffraction. To demonstrate the utility of these compounds, donor $\left(\mathrm{NPh}_{2}\right)$ substituted compounds 4-diphenylamino-2,7-di-(tert-butyl)pyrene and 4,9-bis(diphenylamino)-2,7-di-(tert-butyl)pyrene (2) have been synthesized on a gram scale. Acceptor $\left(\mathrm{BMes}_{2}\right)$ substituted compounds 4,9-bis(BMes 2$)$ pyrene (3) and 4,9-bis(BMes 2 )-1,2,3,6,7,8-hexahydropyrene (4) were synthesized for comparison. The photophysical and electrochemical properties of compounds 1-4 have been studied both experimentally and theoretically. The $S_{0} \rightarrow S_{1}$ transitions of the 4,9-disubstituted pyrenes, 1-3, are allowed, with moderate fluorescence quantum yields and radiative decay rates. The photophysical and electrochemical properties of 1-3 were compared with the 2,6-naphthalenylene-cored compound 4 as well as the previously reported 2,7- and 1,6- pyrenylene-cored compounds.

\section{INTRODUCTION}

Organic $\pi$-conjugated compounds, such as polycyclic aromatic hydrocarbons (PAHs), are of fundamental importance in organic electronics. ${ }^{1}$ These compounds have been used in flexible organic semiconductor devices and as luminescent 
materials. Because the demands of material properties are diverse, electron donors or acceptors with different strengths are introduced onto the PAH core to adjust the HOMO and LUMO levels of PAHs, and thus their photophysical and electrochemical properties.

\section{Scheme 1. The position numbering system in pyrene and the chemically reactive} positions

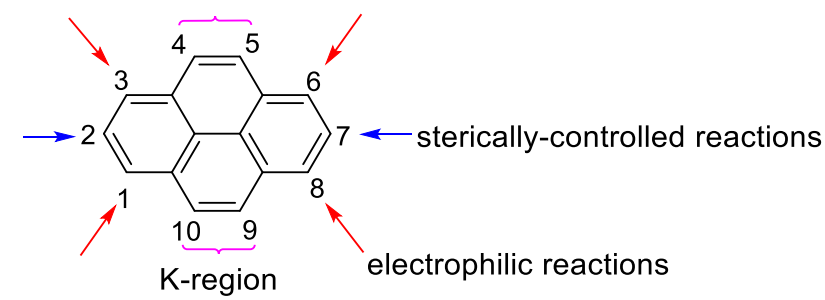

Besides the donor/acceptor strength, the positions at which the PAHs are substituted are very important. For example, the HOMO/LUMO of pyrene have their largest co-efficients at the 1,3,6,8-positions, and thus their mixing with the $\pi$-orbitals of substituents at these positions is very efficient. ${ }^{1}$ In comparison, the $\pi$-orbitals of substituents at the 2,7-positions of pyrene (Scheme 1), which lie on the nodal planes of both the HOMO and LUMO, do not interact with the HOMO and LUMO, but do interact strongly with the HOMO-1 and LUMO+1 of pyrene. ${ }^{2-5}$ Therefore, we have reported recently that the photophysical properties of 1- and 2- substituted pyrenes differ. ${ }^{6}$ We also found that substitution at the 2,7-positions of pyrene with strong donor or acceptor moieties can switch the energy ordering of its HOMO/HOMO-1 and $\mathrm{LUMO} / \mathrm{LUMO}+1$, respectively. ${ }^{3-4,7}$ For example, the unpaired electron in reduced 2-(BMes 2$)$ pyrene and 2,7-bis $\left(\mathrm{BMes}_{2}\right)$ pyrene (i.e. their radical anions) is delocalized between the $-\mathrm{BMes}_{2}$ groups and pyrene. ${ }^{7}$

While the 1,3,6,8-positions of pyrene can be easily substituted by direct electrophilic reactions, ${ }^{1}$ such as halogenation, the sterically directed Ir-catalyzed C-H borylation of pyrene reported by Marder et al. has recently facilitated the synthesis of a wide range of 2- and 2,7- substituted pyrenes, as the pinacol boronates can be converted to numerous other substituents. ${ }^{8-9}$ However, the functionalization of pyrene at the K-region is still limited by either low overall yield in multi-step syntheses, or the variety of structures that could be prepared. ${ }^{10-19}$ For example, 4,9-dibromopyrene was synthesized in three steps, including reduction with sodium, bromination with bromine, and dehydrogenation with Chloranil or DDQ, in low overall yield. In fact, 2,7-di-(tert-butyl)-4,9-dibromopyrene has been synthesized by direct bromination of 2,7-di-(tert-butyl)pyrene, but with a very low yield $(3 \%){ }^{20}$ The synthesis of 4,10 -substituted pyrenes is even less well documented. 
In our recent publications, we noted that Ir-catalyzed C-H borylation can be used to borylate the K-region of pyrene when its 2,7-positions have already been substituted, although the K-region is less active than the 2,7-positions. ${ }^{21-23}$ This approach could provide a more efficient way to synthesize 4,9- and 4,10- disubstituted pyrenes. In this paper, we provide examples of the synthesis of 4-, 4,9- and 4,10- substituted pyrenes. As exemplifying examples (Scheme 2), the electron donor- $\left(\mathrm{NPh}_{2}\right)$ and acceptor$\left(\mathrm{BMes}_{2}\right)^{24-29}$ substituted compounds 1-3 have been synthesized, and their electrochemical and photophysical properties have been studied. We also note that the substituent at the 4- position does not communicate strongly with that at the 9position. The naphthalene-cored bis $\left(\mathrm{BMes}_{2}\right)$ compound $\mathbf{4}$ has been prepared for comparison with $\mathbf{3}$, using 1,2,3,6,7,8-hexahydropyrene instead of naphthalene to achieve a similar $\mathrm{BMes}_{2}$ /arylene twist to that in $\mathbf{3}$.

\section{Scheme 2. The chemical structures of compounds 1-4}
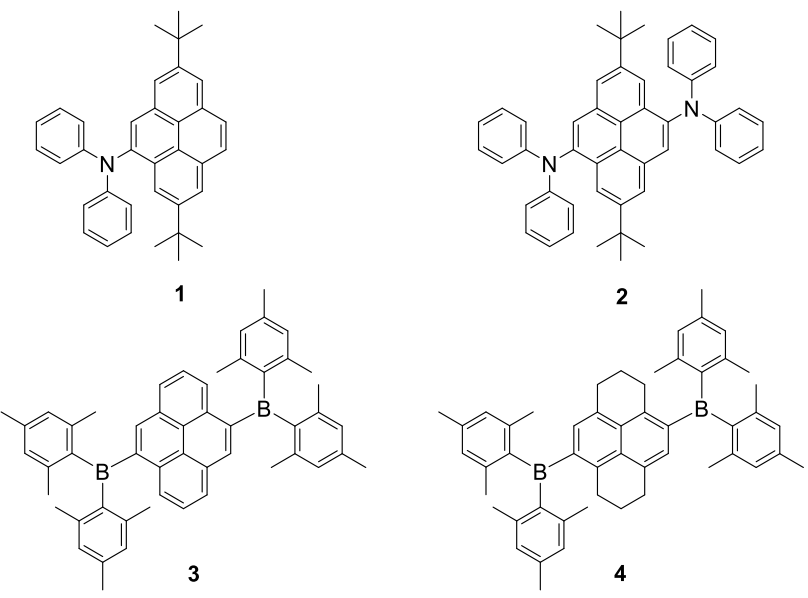

\section{RESULTS AND DISCUSSION}

Synthesis. Firstly, borylation of 2,7-di-(tert-butyl)pyrene using $[\operatorname{Ir}(\mathrm{COD})(\mathrm{OMe})]_{2}(5 \%)$ as the pre-catalyst and 4,4'-di-(tert-butyl)-2,2'-dipyridyl (dtbpy, 10\%) as the ligand in THF solvent gave a mixture of $\mathbf{5}, \mathbf{6}$, and 7 with a ratio of 1:1.8:1.4 (Scheme 3). Chromatography on silica gel, which had been pre-deactived by boric acid, ${ }^{30}$ allowed the separation of the monoboronate ester $\mathbf{5}$ from the mixture of bisboronates $\mathbf{6}$ and $\mathbf{7}$. The monoboronate 5 was converted to the monobromide 8 in a $99 \%$ yield by refluxing with excess $\mathrm{CuBr}_{2}{ }^{31}$ The bisboronates 6 and 7 could not be readily separated by column chromatography, but we noted that the solubility of those two compounds are quite different in hexane, methanol, and ethanol. Thus, the mixture was suspended in methanol in a centrifuge tube, and the centrifuge tube was placed into an ultrasonic bath for $2 \mathrm{~h}$. After centrifugation, the ${ }^{1} \mathrm{H}$ NMR spectrum shows that the undissolved solid is pure $\mathbf{6}$, and the mother liquor contains predominantly 7 contaminated with $\mathbf{6} .^{32}$ The purification of $\mathbf{7}$ is more difficult and only a small amount 
of 7 has been isolated. The boronate esters 5-7 can be very efficient precursors for the preparation of many K-region substituted pyrenes. Boronate ester $\mathbf{6}$ was converted to 2,7-di-(tert-butyl)-4,9-dibromopyrene 9 in 91\% isolated yield, by employing the same procedure as used for the synthesis of $\mathbf{8}$. The overall yield of 2,7-di-(tert-butyl)-4,9-dibromopyrene (9) from 2,7-di-(tert-butyl)pyrene is 21\%, which is much higher than that of previously reported methods. ${ }^{20}$

We also prepared 4,9-dibromopyrene, 13, via the previously reported 'indirect method'. ${ }^{33}$ By reduction of pyrene with 9 eq. of sodium in refluxing pentanol at 150 ${ }^{\circ} \mathrm{C}, 1,2,3,6,7,8$-hexahydropyrene (10) can be isolated in only ca. $20 \%$ yield. Bromination of $\mathbf{1 0}$ gave a white precipitate $(43 \%$ yield $)$, which is 4,9-dibromo-1,2,3,6,7,8-hexahydropyrene $\quad(\mathbf{1 1})^{34}$ contaminated with $10 \%$ of 4,10-dibromo-1,2,3,6,7,8-hexahydropyrene (12). We then checked the ${ }^{1} \mathrm{H}$ NMR spectra of the filtrate, which revealed that it contains a mixture of $\mathbf{1 1}$ and $\mathbf{1 2}$ in a ratio of 1 : 1.7. In fact, a ${ }^{1} \mathrm{H}$ NMR spectrum of the crude reaction mixture reveals that the bromination of $\mathbf{1 0}$ gives $\mathbf{1 1}$ and $\mathbf{1 2}$ in a ratio of $1.7: 1$. Following subsequent dehydrogenation of $\mathbf{1 1}$ with Chloranil or DDQ, the overall yield of $\mathbf{1 3}$ in the three-step procedure from pyrene is only $c a .5 \%$.

\section{Scheme 3. Synthesis of compounds 1-4}
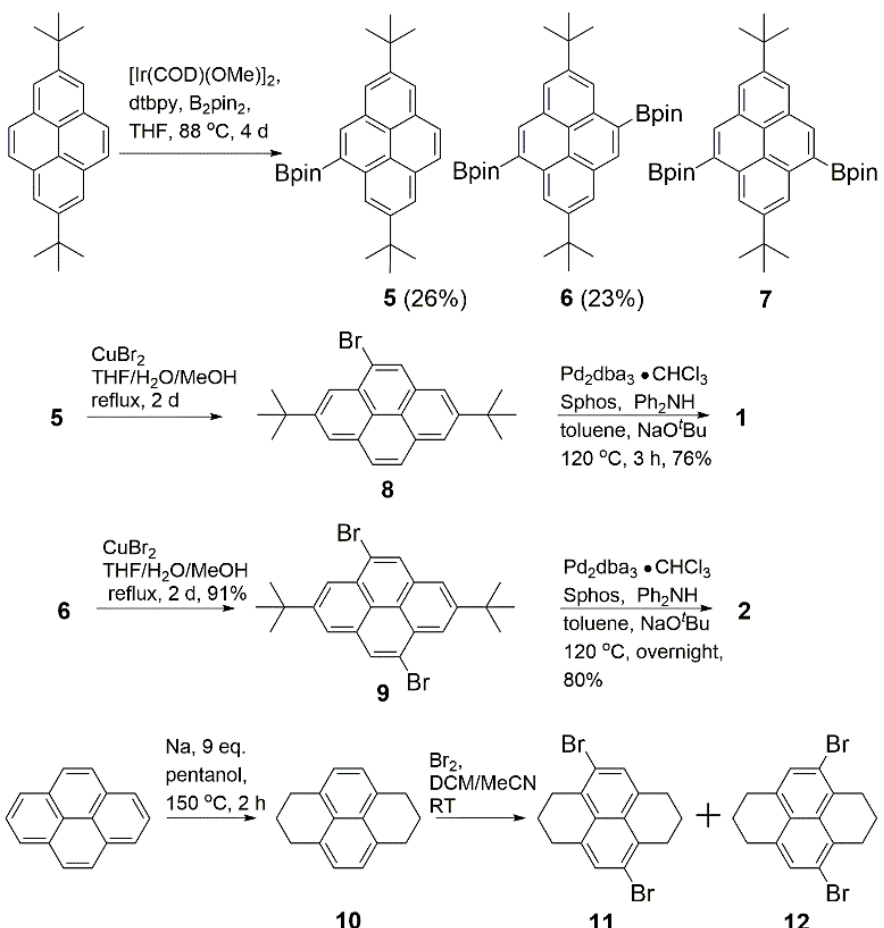

10

11

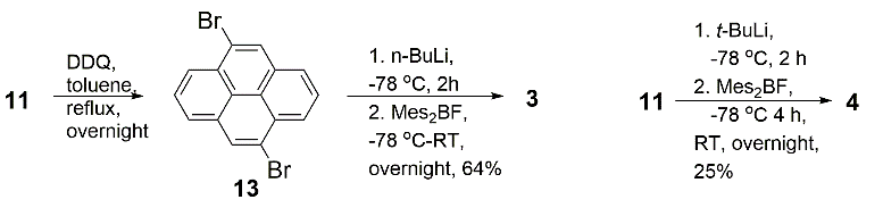


With bromides 8 and 9 in hand, the mono- and bis(diphenylamino)pyrenes $\mathbf{1}$ and $\mathbf{2}$ were synthesized via Buchwald-Hartwig amination, ${ }^{35-36}$ using $\mathrm{Pd}_{2}(\mathrm{dba})_{3} \cdot \mathrm{CHCl}_{3}(0.3$ mol \%; dba $=$ dibenzylideneacetone $)$ as precatalyst, SPhos $(1 \mathrm{~mol} \%$; SPhos $=$ 2-dicyclohexylphosphino-2',6'-dimethoxybiphenyl) as ligand, and $\mathrm{NaO}^{t} \mathrm{Bu}$ as base, in high isolated yields ( $c a .80 \%)$ and on a multi-gram scale. Compounds $\mathbf{3}$ and $\mathbf{4}$ were synthesized in moderate yields by lithiation of $\mathbf{1 3}$ and 11, respectively, followed by borylation with $\mathrm{Mes}_{2} \mathrm{BF}$. While compound 3 was obtained as yellowish crystals, compound $\mathbf{4}$ is a deep yellow crystalline compound, indicating the red-shifted absorption of 4 .

X-ray Crystal Structures. The solid-state structures 1, 3, 4, 6, and 7 were confirmed by single-crystal X-ray diffraction. Crystal data and experimental details are listed in Table S1 in the Supporting Information (SI). Their molecular structures are presented in Figures S1-S5, and the key bond lengths and angles are summarized in Tables S2 and S3 in the SI. There are no strong inter-molecular interactions, such as $\pi$ - $\pi$ stacking, in the crystal structures of $\mathbf{1}, \mathbf{3}, \mathbf{4}, \mathbf{6}$, and 7 . The dihedral angles between the $\mathrm{BC}_{3}$ plane $^{37}$ and the arylene-bridge in 3 (average $43.9(1)^{\circ}$ ) and $4\left(43.7(1)^{\circ}\right)$ are similar. It has been noted that the $\mathrm{C}_{4}-\mathrm{C}_{5}$ and $\mathrm{C}_{9}-\mathrm{C}_{10}$ bonds in the $\mathrm{K}$-region of pyrene can be considered to be isolated $\mathrm{C}=\mathrm{C}$ double bonds, ${ }^{38}$ which are not significantly affected by the substituents at the 2- or 2,7- positions, even in the reduced form of 2,7-bis(BMes 2 )pyrene. ${ }^{3,7}$ However, in all structures reported herein, the $\mathrm{C}_{4}-\mathrm{C}_{5}$ and/or $\mathrm{C}_{9}-\mathrm{C}_{10}$ double bonds are longer than those in unsubstituted pyrene.

Photophysical Properties. The UV-Vis absorption and emission spectra of compounds 1-4 have been measured, and those in hexane are summarized in Figure 1 and Table 1. The lowest energy absorption bands of 1-4 are broad and correspond to intramolecular charge transfer (ICT) transitions (vide infra) between the arylene-core and substituents. The $\mathrm{S}_{0} \rightarrow \mathrm{S}_{1}$ transitions of 1-4 are all allowed, with molar extinction coefficients of 7200-14900 $\mathrm{M}^{-1} \mathrm{~cm}^{-1}$ (Table 1, and Figure S6 in the SI). The two lowest energy absorption bands between 350 and $425 \mathrm{~nm}$ of monoamine 1 are weaker than those of the diamine 2, indicating that they are related to the diphenylamino group(s). There are several intense pyrene-like transitions in the higher energy region $(249,279$, and $337 \mathrm{~nm}$ ) in mono-substituted compound 1, which are either weaker or not noticeable in the disubstituted pyrenes $\mathbf{2}$ and 3. The lowest energy transition of $\mathbf{2}$ in hexane is red-shifted by only $6 \mathrm{~nm}\left(385 \mathrm{~cm}^{-1}\right)$ from that of $\mathbf{1}$. This red-shift is less than the corresponding bathochromic shift of 2,7-bis(BMes 2$)$ pyrene from 2-(BMes 2$)$ pyrene, ${ }^{6-7}$ as well as of 1,6- or 1,3- bis(BMes 2$)$ pyrene from 1-(BMes 2$)$ pyrene. $^{6,} 39$ These indicate that there is less electronic coupling between substituents at the 4- and 9- positions of pyrene than between substituents at the 2- 
and 7-positions, or between substituents at the 1- and 3- or 6-positions. Both the absorption and emission maxima of the naphthalene-bridged compound, 4, are red shifted from those of the pyrene-bridged compounds 1-3, which indicates that the electronic coupling between the two BMes2 groups through the 2,6-naphtalenylene bridge is stronger than that through the 4,9-pyrenylene moiety.
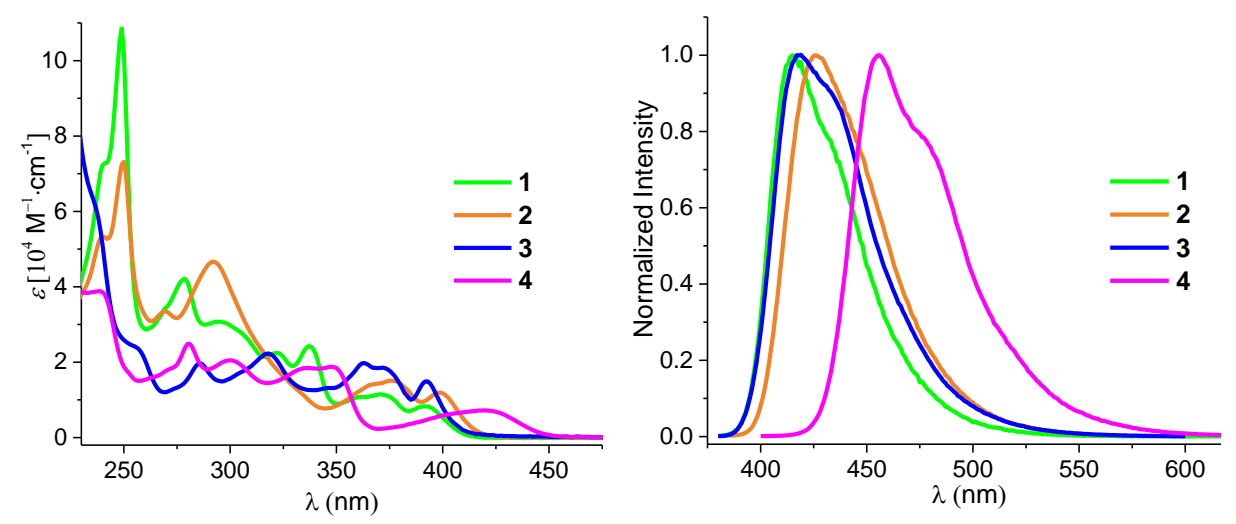

Figure 1. Absorption (left) and normalized emission spectra (right) of 1-4 in hexane.

Table 1. Photophysical properties of compounds 1-4 in hexane. ${ }^{a}$

\begin{tabular}{lllllllll}
\hline & $\begin{array}{r}\lambda_{\mathrm{abs}}{ }^{b} \\
\mathrm{~nm}\end{array}$ & $\begin{array}{c}\varepsilon^{c} \\
\mathrm{M}^{-1} \mathrm{~cm}^{-1}\end{array}$ & $\begin{array}{c}\lambda_{\mathrm{em}} \\
\mathrm{nm}\end{array}$ & $\begin{array}{c}\text { Stokes shift } \\
\mathrm{cm}^{-1}\end{array}$ & $\phi$ & $\begin{array}{l}\tau \\
\mathrm{ns}\end{array}$ & $\begin{array}{l}\tau_{0}{ }^{d} \\
\mathrm{~ns}\end{array}$ & $k_{\mathrm{r}}$ \\
\hline 1 & 392 & 8300 & 415 & 1400 & 0.24 & 3.1 & 13 & 7.7 \\
2 & 398 & 11900 & 426 & 1650 & 0.28 & 4.6 & 16 & 6.3 \\
3 & 392 & 14900 & 419 & 1640 & 0.33 & 5.0 & 15 & 6.7 \\
4 & 420 & 7200 & 456 & 1900 & 0.90 & 14.6 & 16 & 6.3 \\
\hline
\end{tabular}

${ }^{a}$ Fluorescence lifetimes and quantum yields of 1-3 were measured in air, while those of $\mathbf{4}$ were measured under argon because of its long decay time; ${ }^{b}$ absorption maximum; ${ }^{c}$ molar extinction coefficient of the $\mathrm{S}_{0} \rightarrow \mathrm{S}_{1}$ transition and ${ }^{d}$ natural lifetime of the fluorescence $(\tau / \Phi)$.

While the naphthalene-cored compound 4 shows a very high fluorescence quantum yield and modest Stokes shift in hexane, the pyrene-cored compounds 1-3 show moderate quantum yields, with relatively smaller Stokes shifts. The radiative decay rates of all four compounds are similar, being in the range of 6.3-7.7 x 10 $/ \mathrm{s}$, indicating that the $\mathrm{S}_{1} \rightarrow \mathrm{S}_{0}$ transitions are allowed. This is much faster than most 2- and 2,7-substituted pyrenes, ${ }^{3-6}$ but slower than 1 -substituted pyrenes. ${ }^{6}$ The emission spectra of $\mathrm{NPh}_{2}$-substituted compounds $\mathbf{1}$ and $\mathbf{2}$ are strongly dependent on solvent polarity (Figure 2), with solvatochromic shifts of up to 3440 and $3350 \mathrm{~cm}^{-1}$ from hexane to acetonitrile for $\mathbf{1}$ and $\mathbf{2}$, respectively, indicating that the emissions are from 
ICT states which are stabilized in more polar solvents. However, the solvatochromic effects for the BMes 2 -substituted compounds, $\mathbf{3}$ and $\mathbf{4}$, are relatively smaller.
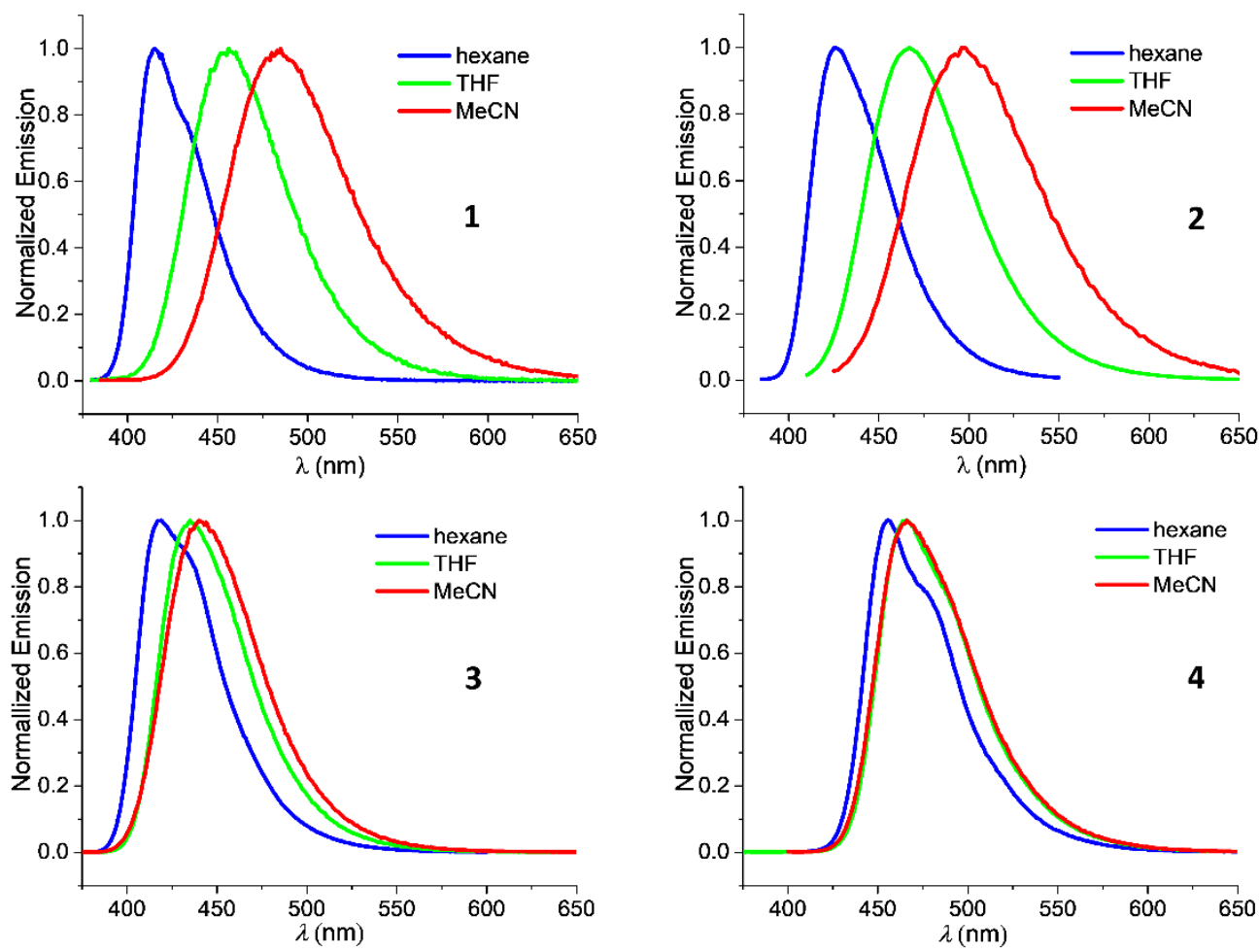

Figure 2. Fluorescence spectra of 1-4 in hexane, THF, and acetonitrile (MeCN).

Electrochemical Properties. Cyclic voltammetry (CV) measurements (Table 2, Figure 3) were performed to estimate the HOMO and LUMO levels of 1-4. The $\mathrm{NPh}_{2}$-substituted pyrenes, 1 and 2, show similar reversible oxidations at $c a$. $0.5 \mathrm{~V}$, which is typical for triarylamines. ${ }^{40}$ They have similar reduction potentials, which are ascribed to a pyrene-localized reduction. The HOMO-LUMO gap of 2, estimated from the CV data, is slightly smaller than that of $\mathbf{1}$, which agrees with the ordering of the HOMO-LUMO gaps estimated from the absorption spectra (Table 2), as well as the DFT calculations (vide infra). We were unable to observe the oxidation of the BMes2-substituted compounds, $\mathbf{3}$ and $\mathbf{4}$. However, the first reduction potential of $\mathbf{3}$ is less negative than those of $\mathbf{1}$ and $\mathbf{2}$, indicating that the BMes2 substituents stabilize the LUMO of pyrene.

A large separation of the two reduction potentials of bis $\left(\mathrm{BMes}_{2}\right)$-arylene compounds often indicates a better conjugation with the arylene bridge, as well as stronger electronic coupling between two BMes 2 groups. ${ }^{7,41-44}$ We found that the separation of the two reduction potentials in the pyrene-based compound 3 of $330 \mathrm{mV}$ is significantly smaller than that in the naphthalene-based compound $4(500 \mathrm{mV})$. Because the distances between the two-boron centers in $\mathbf{3}$ and $\mathbf{4}$ are similar, and the 
arylene/ $\mathrm{BC}_{3}$ twists are identical (Table S2), we can conclude that 2,6-naphthalenylene is a more effective conjugated bridge than 4,9-pyrenylene.

Table 2. Cyclic voltammetric data, ${ }^{a}$ and experimental HOMO and LUMO energies.

\begin{tabular}{llllll}
\hline & $\begin{array}{l}\mathrm{E}_{\mathrm{ox}}{ }^{b} \\
{[\mathrm{~V}]}\end{array}$ & $\begin{array}{l}\mathrm{E}_{\mathrm{red}}{ }^{c} \\
{[\mathrm{~V}]}\end{array}$ & $\begin{array}{l}\mathrm{HOMO}^{d} \\
{[\mathrm{eV}]}\end{array}$ & $\begin{array}{l}\mathrm{LUMO}^{d} \\
{[\mathrm{eV}]}\end{array}$ & $\begin{array}{l}\mathrm{Eg}^{e, f} \\
{[\mathrm{eV}]}\end{array}$ \\
\hline 1 & 0.49 & -2.66 & -5.29 & -2.14 & $3.15(2.95)$ \\
2 & 0.48 & -2.60 & -5.28 & -2.20 & $3.08(2.89)$ \\
3 & -- & $-2.31,-2.64$ & -- & -2.49 & $--(2.88)$ \\
4 & -- & $-2.24,-2.74$ & -- & -2.56 & $--(2.70)$ \\
\hline
\end{tabular}

${ }^{a}$ Potentials are given $v s$. ferrocene/ferrocenium $\left(\mathrm{Fc} / \mathrm{Fc}^{+}\right) ;{ }^{b}$ measured in dichloromethane; ${ }^{c}$ measured in THF; ${ }^{d}$ estimated by assuming that the HOMO of ferrocene lies $4.8 \mathrm{eV}$ below the vacuum level: $\mathrm{HOMO}=-\left(4.80+\mathrm{E}_{\mathrm{ox}}\right) \mathrm{eV} ; \mathrm{LUMO}=-\left(4.80+\mathrm{E}_{\text {red }}\right) \mathrm{eV}{ }^{e}$ the HOMO-LUMO gap is calculated by $E_{\mathrm{g}}=$ LUMO-HOMO, and ${ }^{f}$ the values in parenthesis are optical band gaps estimated from the onsets of the absorption spectra in hexane.

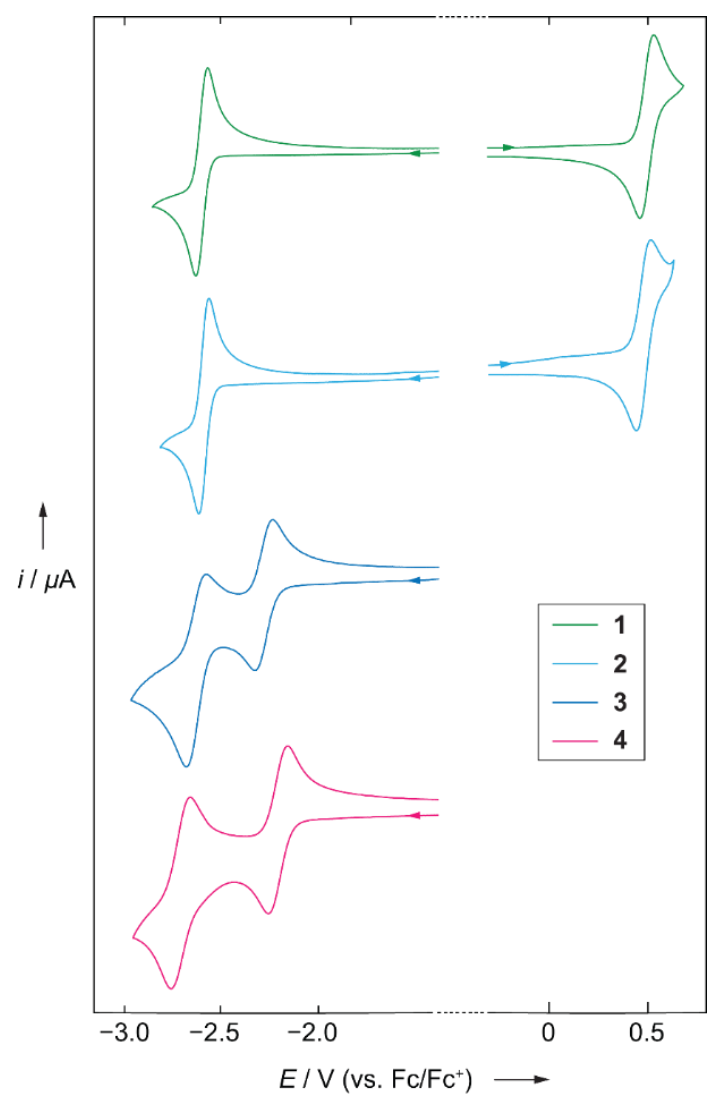

Figure 3. Cyclic voltammograms of compounds 1-4. The reduction potentials were measured in THF and the oxidation potentials in dichloromethane. The supporting electrolyte was $0.1 \mathrm{M} \mathrm{Bu}_{4} \mathrm{NPF}_{6}$ in all experiments. 
Theoretical Studies. To understand further the interaction between pyrene and substituents at its 4- and 4,9-positions, DFT calculations at the B3LYP/6-31G(d) level of theory in the gas phase were performed. The LUMO/LUMO+1 of $\mathbf{1}$ and $\mathbf{2}$, as well as the HOMO of $\mathbf{3}$ and $\mathbf{4}$, are mainly localized on the arylene bridges and are similar to those of the unsubstituted arenes. (Figure 4). The HOMOs of the $\mathrm{NPh}_{2}$-substituted compounds, $\mathbf{1}$ and 2, are out of phase combinations of the pyrene HOMO and the lone pair of nitrogen, destabilized by $0.44 \mathrm{eV}$ and $0.47 \mathrm{eV}$, respectively from the HOMO of pyrene. The LUMO of the $\mathrm{BMes}_{2}$-substituted compounds, 3 and $\mathbf{4}$, are in-phase combinations of the boron empty $p_{z}$ orbital and the LUMO of the $\pi$-bridge. While the LUMO of 3 is stabilized by $0.35 \mathrm{eV}$ from that of pyrene, the stabilization of the LUMO of 4 is much greater, i.e., by $1.23 \mathrm{eV}$ compared to that of 1,2,3,6,7,8-hexahydropyrene (Table S4 in the SI). This agrees with the cyclic voltammetric analysis and the bathochromic shift in the absorption spectrum of $\mathbf{4}$, again, indicating that the mixing of the frontier orbitals in the 2,6-substituted naphthalene derivative is much more effective than that in the 4,9 -substituted pyrene.

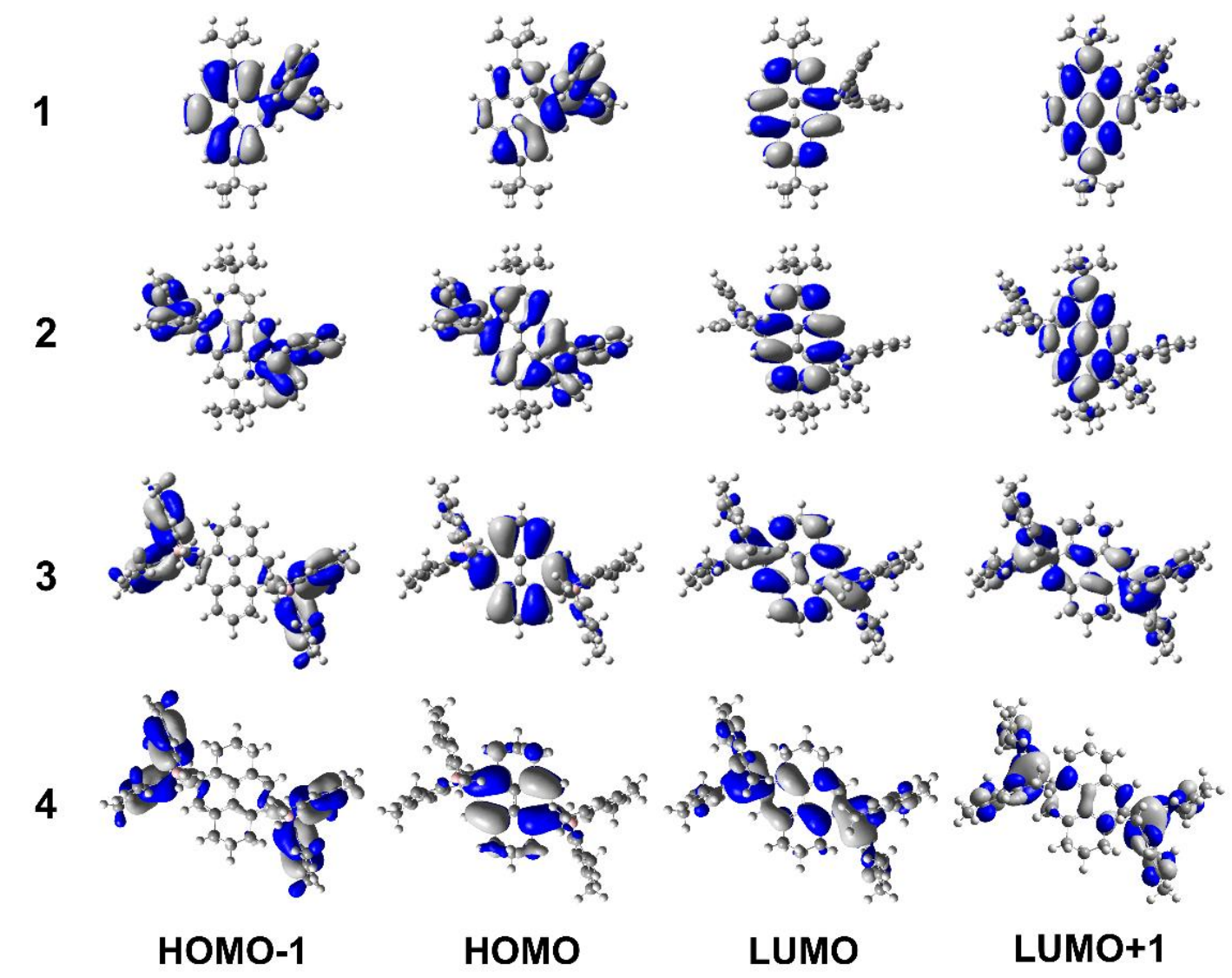

Figure 4. Kohn-Sham frontier molecular orbitals of compounds 1-4 (isodensity value: $\pm 0.015)$. 
TD-DFT calculations at the CAM-B3LYP/6-31G(d) level in the gas phase reveal that the $\mathrm{S}_{0} \rightarrow \mathrm{S}_{1}$ transitions of $\mathbf{1 - 4}$ are predominantly HOMO $\rightarrow$ LUMO transitions (Table S4), all of which are ICT transitions. The $\mathrm{S}_{0} \rightarrow \mathrm{S}_{1}$ transitions of 1-4 are all allowed with oscillator strengths between $0.20-0.54$, while the $S_{0} \rightarrow S_{1}$ transitions of 2and 2,7- substituted pyrenes are forbidden and thus very weak. ${ }^{45}$ The $\mathrm{S}_{0} \rightarrow \mathrm{S}_{1}$ transition energy of $\mathbf{4}$ is much lower than those of $\mathbf{1 - 3}$, in agreement with the photophysical and electrochemical measurements.

\section{CONCLUSIONS}

In conclusion, we have reported a novel, simple, and efficient way to synthesize 4,9-substituted pyrenes. The overall yields of boronate 6 and bromide 9 from pyrene, through Ir-catalyzed $\mathrm{C}-\mathrm{H}$ borylation under mild conditions, are $23 \%$ and $21 \%$, respectively, which are much higher than the previous synthesis of $\mathbf{1 3}$ which employed highly toxic and hazardous reagents. The combination of UV-Vis absorption spectra, time-resolved spectroscopy, as well as TD-DFT calculations reveals that the $\mathrm{S}_{0} \rightarrow \mathrm{S}_{1}$ transitions of all our 4,9-disubstituted pyrenes, 1-3, are allowed. Compounds 1-3 have moderate radiative decay rates and fluorescence quantum yields. Both the absorption and emission maxima of the naphthalene-cored compound $\mathbf{4}$ are red shifted from that of the pyrene-cored compound $\mathbf{3}$. The HOMO-LUMO gap of $\mathbf{3}$, both estimated by absorption spectra and calculated by TD-DFT calculations, is larger than that of 4 . The less negative first reduction potential, as well as the larger splitting of the two reduction potentials of $\mathbf{4}$, compared to 3 , indicates that 4,9-pyrenylene is a less effective conjugated $\pi$-bridge than 2,6-naphthalenylene.

\section{EXPERIMENTAL SECTION}

General Experimental Methods for Synthesis: All reagents were obtained from commercial sources and used as received, with the exception of $[\operatorname{Ir}(\mathrm{COD})(\mu-\mathrm{OMe})]_{2},{ }^{46} \quad$ 2,7-di-(tert-butyl)pyrene, ${ }^{47}$ 4-bromo-2,7-di-(tert-butyl)pyrene, ${ }^{31}$ 4,9-dibromopyrene, ${ }^{34}$ $1,2,3,6,7,8$-hexahydropyrene, ${ }^{33}$ and dimesitylboron fluoride $\left(\mathrm{Mes}_{2} \mathrm{BF}\right)^{48}$ which were synthesized as reported previously. Solvents were HPLC grade, and were treated to remove trace water using a commercial solvent purification system and deoxygenated using the freeze-pump-thaw method. NMR spectra were recorded in $\mathrm{CDCl}_{3}$ and $\mathrm{CD}_{2} \mathrm{Cl}_{2}$ solution on a $500 \mathrm{MHz}\left({ }^{1} \mathrm{H}\right)$ spectrometer. ${ }^{1} \mathrm{H}$ NMR spectra are referenced via the signal of the residual protiated solvent. ${ }^{13} \mathrm{C}$ NMR spectra are referenced via the ${ }^{13} \mathrm{C}$ resonance of the deuterated solvent. ${ }^{11} \mathrm{~B}$ NMR spectra are referenced to external $\mathrm{BF}_{3} \cdot \mathrm{Et}_{2} \mathrm{O}$. MS was performed in $\mathrm{EI}^{+}$mode on a GC-MS and HRMS was performed 
using a Thermo Scientific Exactive Plus Orbitrap MS system with either an Atmospheric Sample Analysis Probe (ASAP) or by Atmospheric Pressure Chemical Ionization (APCI).

Synthesis of 4-diphenylamino-2,7-di-(tert-butyl)pyrene (1): In an argon-filled glovebox, 4-bromo-2,7-di-(tert-butyl)pyrene (1.17 g, $3.0 \mathrm{mmol}, 1 \mathrm{eq}), \mathrm{Pd}_{2} \mathrm{dba}_{3} \cdot \mathrm{CHCl}_{3}$ (30 mg, $0.03 \mathrm{mmol}, 0.01 \mathrm{eq}$ ), SPhos (40 mg, $0.1 \mathrm{mmol}, 0.03 \mathrm{eq}$ ), NaOtBu (500 mg, $5.2 \mathrm{mmol}, 1.7 \mathrm{eq})$, diphenylamine (680 mg, $4.0 \mathrm{mmol}, 1.3 \mathrm{eq})$, and toluene (20 mL) were added to a Young's tube. The tube was then sealed with a PTFE tap, taken out of the glovebox, and heated in an oil bath at $120^{\circ} \mathrm{C}$ for $3 \mathrm{~h}$, until GC-MS monitoring indicated that the reaction was complete. The solution was cooled to r.t., and the solvent and volatiles were removed in vacuo. Purification was performed by flash chromatography through a silica gel column with dichloromethane: pentane 1:9 as the eluent. Recrystallization by layer diffusion of methanol into a dichloromethane solution gave the title compound as a yellow crystalline solid (1.09 g, 76\%).

Mp 168-171 ${ }^{\circ} \mathrm{C}$; ${ }^{1} \mathrm{H}$ NMR: $\left(500 \mathrm{MHz}, \mathrm{CD}_{2} \mathrm{Cl}_{2}\right): 8.26(\mathrm{~d}, J=2 \mathrm{~Hz}, 1 \mathrm{H}), 8.19(\mathrm{~s}, 1 \mathrm{H})$, $8.16(\mathrm{~d}, J=2 \mathrm{~Hz}, 1 \mathrm{H}), 8.09$ (s, $1 \mathrm{H}), 8.04$ (s, $2 \mathrm{H}), 7.88$ (s, 1H), 7.24-7.20 (m, $4 \mathrm{H})$, 7.18-7.16 (m, $4 \mathrm{H}), 6.97(\mathrm{t}, J=7 \mathrm{~Hz}, 2 \mathrm{H}), 1.55(\mathrm{~s}, 9 \mathrm{H}), 1.31(\mathrm{~s}, 9 \mathrm{H}) ;{ }^{13} \mathrm{C}\left\{{ }^{1} \mathrm{H}\right\} \mathrm{NMR}$ : (125 MHz, $\mathrm{CD}_{2} \mathrm{Cl}_{2}$ ): 149.5, 149.1, 149.0, 143.7, 131.61, 131.60, 131.0, 129.5, 128.9, $127.9,127.6,127.4,124.8,122.8,122.6,122.33,122.28,122.25,121.8,120.5,35.52$, 35.45, 32.0, 31.8; $\mathrm{MS}\left(\mathrm{EI}^{+}\right): m / z 481.3\left[M^{+}\right]$; Anal. Calcd for $\mathrm{C}_{36} \mathrm{H}_{35} \mathrm{~N}$ : C, 89.77; $\mathrm{H}$, 7.32; N, 2.91. Found: C, 89.11; H, 7.57; N, 2.92; HRMS $\left(\mathrm{APCI}^{+}\right) \mathrm{m} / z:[M+H]^{+}$Calcd for $\mathrm{C}_{36} \mathrm{H}_{36} \mathrm{~N}_{1}$ 482.2842; Found: 482.2840 .

Synthesis of 4,9-bis(Bpin)-2,7-di-(tert-butyl)pyrene

(6) and 4,10-bis(Bpin)-2,7-(di-tert-butyl)pyrene (7): In an argon-filled glovebox, 2,7-di-(tert-butyl)pyrene (1.26 g, $4 \mathrm{mmol}, 1 \mathrm{eq}), \mathrm{B}_{2} \mathrm{pin}_{2}$ (3.04 g, $12 \mathrm{mmol}, 3 \mathrm{eq}$ ), 4,4'-di-(tert-butyl)-2,2'-bipyridine (dtbpy) (114 $\mathrm{mg}, \quad 0.42 \quad \mathrm{mmol}, \quad 0.1 \quad$ eq), $[\operatorname{Ir}(\mathrm{COD})(\mu-\mathrm{OMe})]_{2}(132 \mathrm{mg}, 0.21 \mathrm{mmol}, 0.05 \mathrm{eq})$, and THF $(5 \mathrm{~mL})$ were added to a Young's tube. The tube was sealed with a PTFE tap and heated at $88^{\circ} \mathrm{C}$ in an oil bath for 4 days. A ${ }^{1} \mathrm{H}$ NMR spectrum reveals that the ratio of compounds 4,9-bis(Bpin)pyrene, 4,10-bis(Bpin)pyrene, and 4-(Bpin)pyrene is 1.8: 1: 1.4 (Figure S7). After removal of the solvent in vacuo, the residue was purified by column chromatography (silica; 1:4 dichloromethane/pentane), to obtain 
4-(Bpin)-2,7-di-(tert-butyl)pyrene (450 $\mathrm{mg}, 1.02 \mathrm{mmol}, 26 \%)$ and a mixture of bis(Bpin)pyrenes.

The bis(Bpin)pyrene mixture was washed with $50 \mathrm{~mL}$ of methanol using an ultrasonic bath to obtain the pure 4,9-bis(Bpin)-2,7-di-(tert-butyl)pyrene (6) as a white solid (520 mg, 23\%).

Mp. > $350{ }^{\circ} \mathrm{C}$ decomp; ${ }^{1} \mathrm{H}$ NMR: $\left(500 \mathrm{MHz}, \mathrm{CDCl}_{3}\right): 9.22$ (s, $\left.2 \mathrm{H}\right), 8.67$ (s, $\left.2 \mathrm{H}\right)$, 8.24 (s, $2 \mathrm{H}), 1.58$ (s, $18 \mathrm{H}), 1.51$ (s, $24 \mathrm{H}) ;{ }^{13} \mathrm{C}\left\{{ }^{1} \mathrm{H}\right\}$ NMR: (125 MHz, $\left.\mathrm{CDCl}_{3}\right): 148.4$,

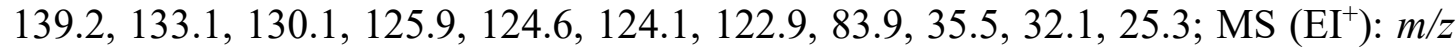
$566[M]^{+}$; HRMS $\left(\mathrm{APCI}^{+}\right) \mathrm{m} / z:[M+H]^{+}$Calcd for $\mathrm{C}_{36} \mathrm{H}_{49} \mathrm{~B}_{2} \mathrm{O}_{4}$ 567.3811; Found: 567.3796 .

The solvent was removed from the washings under vacuum to give a brown powder. Recrystallization by layer diffusion of acetonitrile into a dichloromethane solution gave 4,10-bis(Bpin)-2,7-di-(tert-butyl)pyrene (7) as colorless crystals. A few crystals were selected, and NMR spectra show them to be pure 7, the structure of which was confirmed by single-crystal X-ray diffraction.

${ }^{1} \mathrm{H}$ NMR: (500 MHz, $\mathrm{CDCl}_{3}$ ): 9.16 (s, $\left.2 \mathrm{H}\right), 8.62$ (s, $\left.2 \mathrm{H}\right), 8.25$ (s, $\left.2 \mathrm{H}\right), 1.60$ (s, $\left.9 \mathrm{H}\right)$, 1.54 (s, $9 \mathrm{H}), 1.51$ (s, $24 \mathrm{H}) ;{ }^{13} \mathrm{C}\left\{{ }^{1} \mathrm{H}\right\}$ NMR: $\left(125 \mathrm{MHz}, \mathrm{CDCl}_{3}\right)$ : 148.4, 148.2, 137.9, 133.2, 130.0, 127.2 (brs), 125.4, 123.8, 123.3, 122.7, 83.9, 35.7, 35.2, 32.1, 32.2, 25.2; MS $\left(\mathrm{EI}^{+}\right): m / z 566[M]^{+}$; HRMS $\left(\mathrm{APCI}^{+}\right) m / z:[M+H]^{+}$Calcd for $\mathrm{C}_{36} \mathrm{H}_{49} \mathrm{~B}_{2} \mathrm{O}_{4}$ 567.3811; Found: 567.3811.

Synthesis

4,9-bis(Bpin)-2,7-di-(tert-butyl)pyrene (980 mg, $1.73 \mathrm{mmol}, 1 \mathrm{eq}$ ) was dissolved in a mixture of THF $(20 \mathrm{~mL})$ and methanol $(30 \mathrm{~mL})$. A solution of $\mathrm{CuBr}_{2}(2.76 \mathrm{~g}, 12.4$ mmol, $7.2 \mathrm{eq})$ in water $(30 \mathrm{~mL})$ was added dropwise. The reaction mixture was stirred vigorously at $90{ }^{\circ} \mathrm{C}$ for 2 days, and more $\mathrm{CuBr}_{2}(2.76 \mathrm{~g}, 12.4 \mathrm{mmol}, 7.2 \mathrm{eq})$ was added and then the reaction mixture was stirred at $90{ }^{\circ} \mathrm{C}$ for another 2 days. GC-MS of the reaction mixture showed that the reaction was complete. The crude mixture was extracted with toluene and then passed through a short silica pad with toluene as the eluent. Removal of the solvent gave the title compound (9) as a yellowish solid (740 mg, 91\%). 
Mp 258-261 ${ }^{\circ} \mathrm{C}$; ${ }^{1} \mathrm{H}$ NMR: (500 MHz, $\left.\mathrm{CDCl}_{3}\right): 8.62$ (d, J=2 Hz, $2 \mathrm{H}$,), 8.42 (s, $\left.2 \mathrm{H}\right)$, $8.18(\mathrm{~d}, J=2 \mathrm{~Hz}, 2 \mathrm{H}$ ), 1.60 (s, $18 \mathrm{H}) ;{ }^{13} \mathrm{C}\left\{{ }^{1} \mathrm{H}\right\} \mathrm{NMR}:\left(125 \mathrm{MHz}, \mathrm{CDCl}_{3}\right): 150.2$, 131.3, 131.0, 129.4, 123.1, 123.0, 122.84, 122.76, 35.7, 32.0 ppm; $\mathrm{MS}\left(\mathrm{EI}^{+}\right): \mathrm{m} / z$ 472; Anal. Calcd. for $\mathrm{C}_{24} \mathrm{H}_{24} \mathrm{Br}_{2}$ : C, 61.04; H, 5.12. Found: C, 61.53; H, 5.44; HRMS $\left(\mathrm{ASAP}^{+}\right) m / z$ : $[M+H]^{+}$Calcd for $\mathrm{C}_{24} \mathrm{H}_{25} \mathrm{Br}_{2}$ 473.0297; Found: 473.0283 .

Synthesis of 4,9-bis(diphenylamino)-2,7-di-(tert-butyl)pyrene (2): In an argon-filled glovebox, 4,9-dibromo-2,7-di-(tert-butyl)pyrene (830 mg, $1.77 \mathrm{mmol}, 1 \mathrm{eq}$ ), $\mathrm{Pd}_{2} \mathrm{dba}_{3} \cdot \mathrm{CHCl}_{3}(32 \mathrm{mg}, 0.034 \mathrm{mmol}, 0.02 \mathrm{eq}$ ), SPhos (40 mg, $0.1 \mathrm{mmol}, 0.06 \mathrm{eq})$, $\mathrm{NaO} t \mathrm{Bu}$ (680 mg, $7.1 \mathrm{mmol}, 4 \mathrm{eq}$ ), diphenylamine (598 mg, $3.54 \mathrm{mmol}, 2 \mathrm{eq}$ ), and toluene $(20 \mathrm{~mL})$ were added to a Young's tube. The tube was then sealed with a PTFE tap, taken out of the glovebox, and heated in an oil bath at $120^{\circ} \mathrm{C}$ overnight. The solution was cooled to r.t., and the solvent and volatiles were removed in vacuo. After passage through a short silica pad with chloroform as the eluent and removal of all the solvent, the residue was recrystallized by layer diffusion of ethanol into a chloroform solution to give the title compound (2) as an off-white crystalline solid (922 mg, $80 \%)$.

$\mathrm{Mp}>350{ }^{\circ} \mathrm{C}$ decomp.; ${ }^{1} \mathrm{H}$ NMR: $\left(500 \mathrm{MHz}, \mathrm{CDCl}_{3}\right): \delta=8.21(\mathrm{~d}, J=2 \mathrm{~Hz}, 2 \mathrm{H}), 7.99$ $(\mathrm{d}, J=2 \mathrm{~Hz}, 2 \mathrm{H}), 7.89$ (s, $2 \mathrm{H}), 7.24-7.19(\mathrm{~m}, 16 \mathrm{H}), 6.99-6.95(\mathrm{~m}, 4 \mathrm{H}) \mathrm{ppm} ;{ }^{13} \mathrm{C}\left\{{ }^{1} \mathrm{H}\right\}$ NMR: (125 MHz, $\mathrm{CDCl}_{3}$ ): 148.9, 148.8, 143.2, 131.7, 129.3, 128.5, 127.3, 123.4, 122.5, 122.03, 121.99, 120.2, 35.3, 31.7 ppm; HRMS $\left(\mathrm{ASAP}^{+}\right) \mathrm{m} / \mathrm{z}:[M+\mathrm{H}]^{+}$Calcd for $\mathrm{C}_{48} \mathrm{H}_{45} \mathrm{~N}_{2}$ 649.3577; Found: 649.3588 .

Synthesis of 4,9-bis(BMes 2$)$ pyrene (3): 4,9-Dibromopyrene (210 mg, $0.58 \mathrm{mmol}, 1 \mathrm{eq})$ was placed in a Schlenk tube which was then evacuated and refilled with argon before dry and degassed THF $(10 \mathrm{~mL})$ was added. The suspension was cooled to $-78{ }^{\circ} \mathrm{C}$ and then $n$-BuLi in hexane (2.5 M, 0.6 mL, $1.5 \mathrm{mmol}, 2.6 \mathrm{eq})$ was added. The suspension was stirred for a further $2 \mathrm{~h}$ at $-78^{\circ} \mathrm{C}$, before $\mathrm{Mes}_{2} \mathrm{BF}$ (380 mg, $1.4 \mathrm{mmol}, 2.4 \mathrm{eq}$ ) was added. The mixture was then stirred for another $2 \mathrm{~h}$ at $-78^{\circ} \mathrm{C}$ before warming to room temperature and being stirred overnight. Methanol $(1 \mathrm{~mL})$ was added to quench the reaction. Purification was performed by chromatography on silica gel with dichloromethane: pentane $1: 10$ as the eluent to give a white solid. Further 
recrystallization by cooling a hot chloroform solution gave the title compound as a white powder (260 mg, 64\%).

$\mathrm{Mp}>350{ }^{\circ} \mathrm{C} ;{ }^{1} \mathrm{H} \mathrm{NMR}\left(\mathrm{CDCl}_{3}, 500 \mathrm{MHz}\right): \delta=8.18\left(\mathrm{dd}, J_{1}=8 \mathrm{~Hz}, J_{2}=1 \mathrm{~Hz}, 2 \mathrm{H}\right)$, 8.14 (s, 2 H), 8.04 (d, $J=8$ Hz, 2 H), 7.71-7.68 (m, 2 H), 6.81 (s, 8 H), 2.32 (s, 12 H), 2.03 (br s, $24 \mathrm{H}) \mathrm{ppm} ;{ }^{13} \mathrm{C}\left\{{ }^{1} \mathrm{H}\right\} \mathrm{NMR}\left(\mathrm{CDCl}_{3}, 125 \mathrm{MHz}\right): \delta=147.2,143.6,141.0$, 139.2 , 137.5, 133.2, 131.1, 128.6, 127.0, 126.9, 126.1, 125.9, 23.4, 21.5 ppm; ${ }^{11} \mathrm{~B}$ $\operatorname{NMR}\left(161 \mathrm{MHz}, \mathrm{CDCl}_{3}\right): \delta=76 \mathrm{ppm}$; HRMS $\left(\mathrm{APCI}^{+}\right) m / z:[M-H]^{+}$Calcd for $\mathrm{C}_{52} \mathrm{H}_{53} \mathrm{~B}_{2}^{+}$699.4328; Found 699.4324.

Synthesis of 4,9-bis(BMes 2$)-1,2,3,6,7,8$-hexahydropyrene (4): 4,9-Dibromo-1,2,3,6,7,8-hexahydropyrene (360 $\mathrm{mg}, 1.0 \mathrm{mmol}, 1 \mathrm{eq})$ was placed in a Schlenk tube which was then evacuated and refilled with argon before dry and degassed THF $(10 \mathrm{~mL})$ was added. The suspension was cooled to $-78{ }^{\circ} \mathrm{C}$, and then $t$-BuLi in pentane (1.7 M, $2.6 \mathrm{~mL}, 4.4 \mathrm{mmol}, 4.4 \mathrm{eq})$ was added. The suspension was stirred for a further $2 \mathrm{~h}$ at $-78{ }^{\circ} \mathrm{C}$, before $\mathrm{Mes}_{2} \mathrm{BF}(630 \mathrm{mg}, 2.4 \mathrm{mmol}, 2.4 \mathrm{eq}$ ) was added. The mixture was stirred for another $4 \mathrm{~h}$ at $-78{ }^{\circ} \mathrm{C}$ before warming to room temperature and being stirred overnight. Methanol $(1 \mathrm{~mL})$ was added to quench the reaction. Purification was performed by chromatography on silica with dichloromethane: pentane $1: 10$ as the eluent. After removing the solvent, recrystallization by layer diffusion of ethyl acetate into a toluene solution gave the title compound as a yellow powder (177 mg, 25\%).

Mp 324-327 ${ }^{\circ} \mathrm{C} ;{ }^{1} \mathrm{H}$ NMR $\left(\mathrm{CDCl}_{3}, 500 \mathrm{MHz}\right): \delta=6.98(\mathrm{~s}, 2 \mathrm{H}), 6.77(\mathrm{~s}, 8 \mathrm{H})$, 2.86-2.81 (m, $8 \mathrm{H}), 2.29$ (s, $12 \mathrm{H}), 1.99(\mathrm{~s}, 24 \mathrm{H}), 1.82-1.77(\mathrm{~m}, 4 \mathrm{H}) \mathrm{ppm} ;{ }^{13} \mathrm{C}\left\{{ }^{1} \mathrm{H}\right\}$ NMR ( $\left.\mathrm{CDCl}_{3}, 125 \mathrm{MHz}\right): \delta=143.7,143.4,140.5,139.3,138.8,134.6,131.2,128.4$, 128.3, 32.2, 31.9, 23.9, 23.3, 21.4 ppm; ${ }^{11} \mathrm{~B}$ NMR (161 MHz, CDCl3): $\delta=78$ ppm; HRMS (APCI $\left.{ }^{+}\right) m / z:[M-\mathrm{H}]^{+}$Calcd for $\mathrm{C}_{52} \mathrm{H}_{57} \mathrm{~B}_{2}$ 703.4641; Found 703.4648.

Bromination of 1,2,3,6,7,8-hexahydropyrene: A solution of 1,2,3,6,7,8-hexahydropyrene (4 g, $19.2 \mathrm{mmol}, 1 \mathrm{eq})$ in dichloromethane (75 mL) was placed in a $250-\mathrm{mL}$ round bottom flask, and a solution of bromine $(2 \mathrm{~mL}, 38.8 \mathrm{mmol}$, $2 \mathrm{eq})$ in dichloromethane $(10 \mathrm{~mL})$ was added dropwise in $1 \mathrm{~h}$. The solution was stirred for an additional $2 \mathrm{~h}$ during which a white precipitate formed. After filtration, a ${ }^{1} \mathrm{H}$ 
NMR spectrum (Figure S8) of the precipitate (3.4 g, crude yield 48\%) shows that it contains $\quad 90 \% \quad 4,9$-diboromo-1,2,3,6,7,8-hexahydropyrene (11) and 10\% 4,10-diboromo-1,2,3,6,7,8-hexahydropyrene (12). The ${ }^{1} \mathrm{H}$ NMR spectrum (Figure S9) of the filtrate was measured, revealing it to contain $37 \% 11$ and $63 \% 12$. The solvent was removed from the filtrate to give $3.7 \mathrm{~g}$ of a pale solid (crude yield 52\%), which was dissolved together with the precipitate in chloroform. The ${ }^{1} \mathrm{H}$ NMR spectrum (Figure S10) of this solution shows that it contains 11 and 12 with a ratio of $1.7: 1$. Pure $\mathbf{1 1}$ was isolated by recrystallization of crude $\mathbf{1 1}$ from chloroform.

Photophysics: All measurements were performed in standard quartz cuvettes $(1 \mathrm{~cm} \times$ $1 \mathrm{~cm})$. All solutions for photophysical measurements had a concentration of ca. $1 \times$ $10^{-5} \mathrm{M}$, except where stated. UV-vis absorption spectra were recorded using a diode-array UV-visible spectrophotometer. All luminescence properties were recorded using a spectrometer equipped with double monochromators for both excitation and emission, operating in right-angle geometry mode, and all spectra were fully corrected for the spectral response of the instrument. The fluorescence quantum yields were measured using a calibrated integrating sphere (150 $\mathrm{mm}$ inner diameter). Fluorescence lifetimes were recorded using the time-correlated single-photon counting (TCSPC) method. Solutions were excited at $376.6 \mathrm{~nm}$ with a picosecond pulsed diode laser (pulse width: $72.6 \mathrm{ps}$ ) at repetition rates of 1-5 $\mathrm{MHz}$ and lifetime data were recorded at the emission maxima. The instrument response functions (IRF) were ca. 950 ps fwhm. Decays were recorded to 10000 counts in the peak channel with a record length of at least 4000 channels. Iterative reconvolution of the IRF with one decay function and nonlinear least-squares analysis were used to analyze the data. The quality of all decay fits was judged to be satisfactory based on the calculated values of the reduced $\chi^{2}$ and Durbin-Watson parameters and visual inspection of the weighted and autocorrelated residuals.

Electrochemistry: A potentiostat with a standard three-electrode cell configuration was employed using a platinum disk working electrode, a platinum wire counter electrode, and a silver wire, separated by a Vycor tip, serving as the reference electrode. Formal redox potentials are referenced to the ferrocene/ferrocenium $\left(\left[\mathrm{Cp}_{2} \mathrm{Fe}\right]^{+/ 0}\right)$ redox couple as an internal standard. Measurements were performed using $0.1 \mathrm{M}$ tetra- $n$-butylammonium hexafluorophosphate $\left(\left[n-\mathrm{Bu}_{4} \mathrm{~N}\right]\left[\mathrm{PF}_{6}\right]\right)$ as the 
supporting electrolyte with a scan rate of $250 \mathrm{mV} / \mathrm{s}$. Compensation for resistive losses ( $i R$ drop) was employed for all measurements.

Crystal structure determination Crystals suitable for single-crystal X-ray diffraction were selected, coated in perfluoropolyether oil, and mounted on sample holders. Diffraction data were collected on 4-circle diffractometers with CCD or CPAD area detectors, using $\mathrm{Mo}-\mathrm{K} \alpha$ radiation monochromated by graphite or multi-layer focusing mirrors. The crystals were cooled to $100 \mathrm{~K}$. The images were processed and corrected for Lorentz-polarization effects and absorption. The structures were solved using the intrinsic phasing method (SHELXT) ${ }^{49}$ and Fourier expansion technique. All non-hydrogen atoms were refined in anisotropic approximation, with hydrogen atoms 'riding' in idealized positions, by full-matrix least squares against $F^{2}$ of all data, using SHELXL ${ }^{50}$ software. Diamond ${ }^{51}$ software was used for graphical representation. Full structural information has been deposited with Cambridge Crystallographic Data Centre. CCDC-1586515 (1), 1586511 (3), 1586512 (4), 1586513 (6), and 1586514 (7).

Theoretical Methods All calculations (DFT and TD-DFT) were carried out with the Gaussian 09 (rev. D.01) program package. ${ }^{52}$ The ground-state geometries were optimized using the B3LYP functional in combination with the $6-31+\mathrm{G}(\mathrm{d})$ basis set. The molecular structures obtained from single-crystal X-ray diffraction of $\mathbf{1}, \mathbf{3}$, and $\mathbf{4}$ were used as the starting geometries. The optimized geometries were confirmed to be local minima by performing frequency calculations and obtaining only positive frequencies. Based on these optimized structures, the gas-phase vertical transitions were calculated (singlets, 10 states) by TD-DFT using the CAM-B3LYP functional in combination with the $6-31+G(d)$ basis set. No symmetry constraints were used in any of the calculations.

\section{ASSOCIATED CONTENT}

\section{Supporting Information}

The Supporting Information is available free of charge on the ACS Publications website.

NMR spectra, additional data of theoretical, photophysical, and single-crystal X-ray diffraction studies.

Crystallographic data in CIF format. 


\section{AUTHOR INFORMATION}

\section{Corresponding Author}

*Email: todd.marder@uni-wuerzburg.de

\section{Present Addresses}

+ Fachbereich Chemie, Universität Konstanz, 78457 Konstanz, Germany.

$\uparrow$ School of Pharmacy, Queen's University Belfast, 97 Lisburn Road, BT9 7BL

Belfast, UK.

\section{Author Contributions}

All authors have approved the final version of the manuscript.

\section{ACKNOWLEDGMENT}

We thank Dr. Christian Ehrenreich and Dr. Philipp Stoessel of Merck Ltd. for suggestions and helpful discussions, the Bavarian State Ministry of Science, Research, and the Arts through the Collaborative Research Network "Solar Technologies go Hybrid", the DFG (GRK 2112) and the of University of Würzburg for financial support.

\section{REFERENCES}

1. Figueira-Duarte, T. M.; Müllen, K. Chem. Rev. 2011, 111, 7260-7314.

2. Müllen, K. Helv. Chim. Acta 1978, 61, 2307-2317.

3. Merz, J.; Fink, J.; Friedrich, A.; Krummenacher, I.; Al Mamari, H. H.; Lorenzen, S.; Haehnel, M.; Eichhorn, A.; Moos, M.; Holzapfel, M.; Braunschweig, H.; Lambert, C.; Steffen, A.; Ji, L.; Marder, T. B. Chem. Eur. J. 2017, 23, 13164-13180.

4. Ji, L.; Lorbach, A.; Edkins, R. M.; Marder, T. B. J. Org. Chem. 2015, 80, 5658-5665.

5. Kurata, R.; Ito, A.; Gon, M.; Tanaka, K.; Chujo, Y. J. Org. Chem. 2017, 82, 5111-5121.

6. Crawford, A. G.; Dwyer, A. D.; Liu, Z.; Steffen, A.; Beeby, A.; Pålsson, L.-O.; Tozer, D. J.; Marder, T. B. J. Am. Chem. Soc. 2011, 133, 13349-13362.

7. Ji, L.; Edkins, R. M.; Lorbach, A.; Krummenacher, I.; Brückner, C.; Eichhorn, A.; Braunschweig, H.; Engels, B.; Low, P. J.; Marder, T. B. J. Am. Chem. Soc. 2015, 137, 6750-6753.

8. Coventry, D. N.; Batsanov, A. S.; Goeta, A. E.; Howard, J. A. K.; Marder, T. B.; Perutz, R. N. Chem. Commun. 2005, 41, 2172-2174.

9. Crawford, A. G.; Liu, Z.; Mkhalid, I. A. I.; Thibault, M.-H.; Schwarz, N.; Alcaraz, G.; Steffen, A.; Collings, J. C.; Batsanov, A. S.; Howard, J. A. K.; Marder, T. B. Chem. Eur. J. 2012, 18, 5022-5035.

10. Casas-Solvas, J. M.; Howgego, J. D.; Davis, A. P. Org. Biomol. Chem. 2014, 12, 212-232.

11. Feng, X.; Hu, J.-Y.; Redshaw, C.; Yamato, T. Chem. Eur. J. 2016, 22, 11898-11916.

12. Feng, X. Synthesis and Photophysical Properties of Pyrene-Based Blue Light-Emitting Monomers. Ph. D. Thesis, Saga University, Saga, Japan, 2013. 
13. Hu, J. Y.; Ni, X. L.; Feng, X.; Era, M.; Elsegood, M. R.; Teat, S. J.; Yamato, T. Org. Biomol. Chem. 2012, 10, 2255-2262.

14. Sasaki, S.; Suzuki, S.; Igawa, K.; Morokuma, K.; Konishi, G. I. J. Org. Chem. 2017, 82, 6865-6873.

15. Lee, J.; Lee, H.; Jung, H.; Jo, M.; Park, J. SID Symp. Dig. Tech. Pap. 2016, 47, 1714-1716.

16. Zöphel, L.; Enkelmann, V.; Müllen, K. Org. Lett. 2013, 15, 804-807.

17. Zöphel, L.; Beckmann, D.; Enkelmann, V.; Chercka, D.; Rieger, R.; Müllen, K. Chem. Commun. 2011, 47, 6960-6962.

18. Feng, X.; Hu, J.-Y.; Iwanaga, F.; Seto, N.; Redshaw, C.; Elsegood, M. R. J.; Yamato, T. Org. Lett. 2013, 15, 1318-1321.

19. Mochida, K.; Kawasumi, K.; Segawa, Y.; Itami, K. J. Am. Chem. Soc. 2011, 133, 10716-10719.

20. Takaku, K.; Kitamura, T.; Watanabe, T.; Yonekuta, Y. Organic Electroluminescence Element. US 2014/0299851 A1, Oct. 9, 2014.

21. Liu, Z.; Wang, Y.; Chen, Y.; Liu, J.; Fang, Q.; Kleeberg, C.; Marder, T. B. J. Org. Chem. 2012, 77, 7124-7128.

22. Ji, L.; Fucke, K.; Bose, S. K.; Marder, T. B. J. Org. Chem. 2015, 80, 661-665.

23. Eliseeva, M. N.; Scott, L. T. J. Am. Chem. Soc. 2012, 134, 15169-15172.

24. Ji, L.; Griesbeck, S.; Marder, T. B. Chem. Sci. 2017, 8, 846-863.

25. Wakamiya, A.; Yamaguchi, S. Bull. Chem. Soc. Jpn. 2015, 88, 1357-1377.

26. Ren, Y.; Jäkle, F. Dalton Trans. 2016, 45, 13996-14007.

27. Jäkle, F. Chem. Rev. 2010, 110, 3985-4022.

28. Hudson, Z. M.; Wang, S. Acc. Chem. Res. 2009, 42, 1584-1596.

29. Li, S. Y.; Sun, Z. B.; Zhao, C. H. Inorg. Chem. 2017, 56, 8705-8717.

30. Hitosugi, S.; Tanimoto, D.; Nakanishi, W.; Isobe, H. Chem. Lett. 2012, 41, 972-973.

31. Bedard, A. C.; Vlassova, A.; Hernandez-Perez, A. C.; Bessette, A.; Hanan, G. S.; Heuft, M. A.; Collins, S. K. Chem. Eur. J. 2013, 19, 16295-16302.

32. If the solid is not pure, the ultrasonication and centrifugation process can be repeated once or twice.

33. Pratap, R.; Tominaga, Y.; Lee, M. L.; Castle, R. N. J. Heterocycl. Chem. 1981, 18, 973-975.

34. Gonzalez, A. Z.; Benitez, D.; Tkatchouk, E.; Goddard III, W. A.; Toste, F. D. J. Am. Chem. Soc. 2011, 133, 5500-5507.

35. Surry, D. S.; Buchwald, S. L. Chem. Sci. 2011, 2, 27-50.

36. Ruiz-Castillo, P.; Buchwald, S. L. Chem. Rev. 2016, 116, 12564-12649.

37. Each boron atom is sp2 hybridized and in the same plane as the three bonded carbon atoms, which is called the $\mathrm{BC} 3$ plane.

38. Clar, E.; Schoental, R., Polycyclic hydrocarbons. Academic Press: New York, 1964.

39. Yuan, N.; Wang, W.; Fang, Y.; Zuo, J.; Zhao, Y.; Tan, G.; Wang, X. Organometallics 2017, 36, 2498-2501.

40. Zhang, Z.; Edkins, R. M.; Nitsch, J.; Fucke, K.; Steffen, A.; Longobardi, L. E.; Stephan, D. W.; Lambert, C.; Marder, T. B. Chem. Sci. 2015, 6, 308-321.

41. Kaim, W.; Hosmane, N. S.; Záliš, S.; Maguire, J. A.; Lipscomb, W. N. Angew. Chem. Int. Ed. 2009, 48, 5082-5091.

42. Fiedler, J.; Zališ, S.; Klein, A.; Hornung, F. M.; Kaim, W. Inorg. Chem. 1996, 35, 3039-3043. 
43. Schulz, A.; Kaim, W. Chem. Ber. 1989, 122, 1863-1868.

44. Kaim, W.; Schulz, A. Angew. Chem., Int. Ed. Engl. 1984, 23, 615-616.

45. The S0->S1 transition in 1-substituted pyrenes is also forbidden; the strong absorption at lowest energy is the superimposition of $\mathrm{S} 0->\mathrm{S} 1$ and $\mathrm{S} 0->\mathrm{S} 2$ transitions

46. Uson, R.; Oro, L. A.; Cabeza, J. A.; Bryndza, H. E.; Stepro, M. P. Inorg. Synth. 1985, 23, 126-130.

47. Berg, A.; Jakobsen, J.; Johansen, S. R. Acta Chem. Scand. 1969, 23, 567-575.

48. Pelter, A.; Smith, K.; Brown, H. C., Borane Reagents. Academic Press: London, 1988; p 428-429.

49. Sheldrick, G. M. Acta Crystallogr. A 2015, A71, 3-8.

50. Sheldrick, G. M. Acta Crystallogr. A 2008, A64, 112-122.

51. Brandenburg, K. Diamond (version $3.2 \mathrm{i}$ ), Crystal and molecular structure visualization, crystal impact H. Putz \& K. Brandenburg GbR, Bonn (Germany). 2012

52. Frisch, M. J.; Trucks, G. W.; Schlegel, H. B.; Scuseria, G. E.; Robb, M. A.; Cheeseman, J. R.; Scalmani, G.; Barone, V.; Mennucci, B.; Petersson, G. A.; Nakatsuji, H.; Caricato, M.; Li, X.; Hratchian, H. P.; Izmaylov, A. F.; Bloino, J.; Zheng, G.; Sonnenberg, J. L.; Hada, M.; Ehara, M.; Toyota, K.; Fukuda, R.; Hasegawa, J.; Ishida, M.; Nakajima, T.; Honda, Y.; Kitao, O.; Nakai, H.; Vreven, T.; Montgomery Jr., J. A.; Peralta, J. E.; Ogliaro, F. o.; Bearpark, M. J.; Heyd, J.; Brothers, E. N.; Kudin, K. N.; Staroverov, V. N.; Kobayashi, R.; Normand, J.; Raghavachari, K.; Rendell, A. P.; Burant, J. C.; Iyengar, S. S.; Tomasi, J.; Cossi, M.; Rega, N.; Millam, N. J.; Klene, M.; Knox, J. E.; Cross, J. B.; Bakken, V.; Adamo, C.; Jaramillo, J.; Gomperts, R.; Stratmann, R. E.; Yazyev, O.; Austin, A. J.; Cammi, R.; Pomelli, C.; Ochterski, J. W.; Martin, R. L.; Morokuma, K.; Zakrzewski, V. G.; Voth, G. A.; Salvador, P.; Dannenberg, J. J.; Dapprich, S.; Daniels, A. D.; Farkas, d. n.; Foresman, J. B.; Ortiz, J. V.; Cioslowski, J.; Fox, D. J. Gaussian 09 Revision D.01, Gaussian, Inc.: Wallingford, CT, USA, 2009. 